\title{
Investigating the Effect of E-management on Customer Service Performance
}

\author{
Mohammed A. Elsaadani \\ Jubail University College, Kingdom of Saudi Arabia
}

saadanim@ucj.edu.sa

\begin{abstract}
The present study aims to investigate the effect of e-management on customer service performance for a group of business organizations in Alexandria - Egypt. The directory of Egyptian Ministry of Trade and Industry was surveyed in order to randomly select the participating organizations. 485 businesses randomly selected representing $25 \%$ of the total population, of which only 391 organizations expressed their willingness to participate. 263 questionnaires were distributed, but only 226 were collected representing $30 \%$ of the study population. Experts comments were used to check the validity of the study instrument, and the reliability of questions was calculated as 93\% using Cronbach's Alpha coefficient. The statistical methods used for data analysis are frequencies, relative frequencies, percentages, averages, order of the responses, Pearson correlation coefficient, Cronbach's Alpha coefficient, confirmatory factorial analysis, central tendency (mean), dispersion (standard deviation), Pearson coefficient, simple linear regression, T-Test, determinant coefficient, and one-way ANOVA. The probability level for a test of statistical significance for the study is $\mathrm{p}<.05$, to ensure a $95 \%$ confidence in generalization of the findings. Study findings assert research hypothesis that there is a statistically significant positive relationship between e-management and customer service performance.
\end{abstract}

Keywords: e-management; performance; customer services; business organizations. 


\title{
استكشاف أثر الإدارة الإلكترونية على أداء خدمات العملاء
}

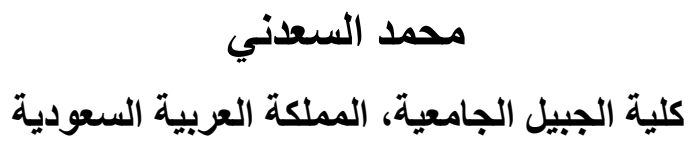

saadanim@ucj.edu.sa

\begin{abstract}
الملخص
تهدف الدر اسة الحالية إلى استكثناف أثر الإدارة الإلكترونية على أداء خدمات العملاء لمؤسسات الأعمال في مدينة الإسكندرية

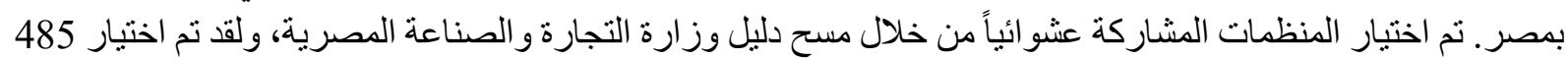

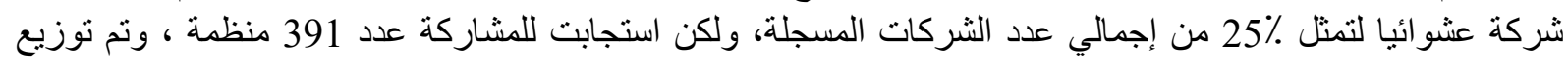

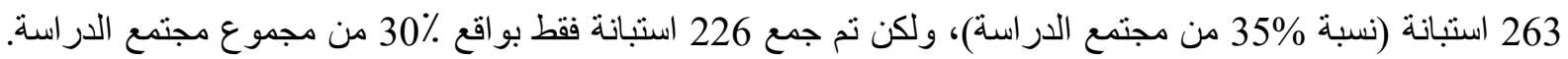

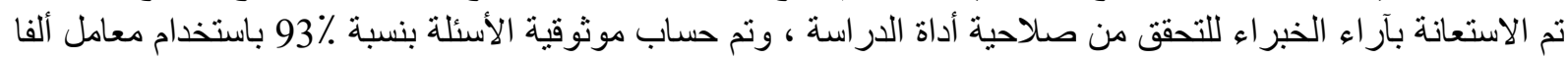

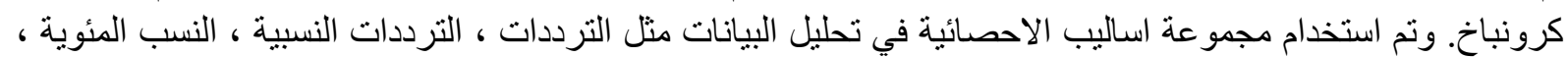

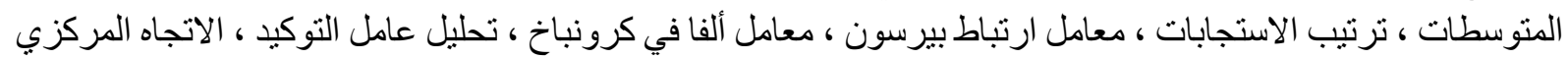

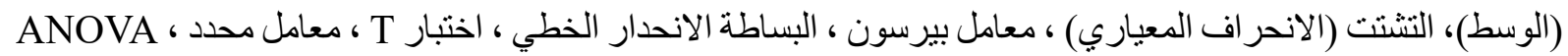

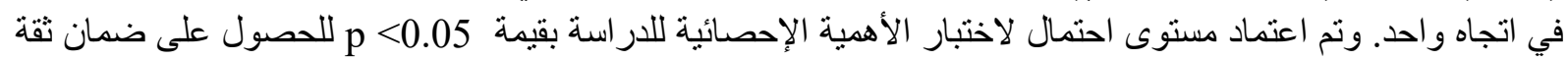

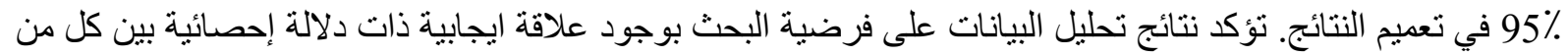

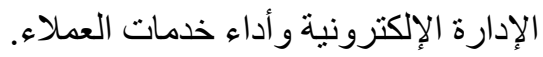

الكلمات الألة: الإدارة الإلكترونية؛ الأداء؛ خدمات العملاء؛ منظمات الأعمال.

\section{Introduction}

The current study aims to investigate the effect of e-management on customer service performance for a group of business organizations in Alexandria - Egypt. Thus, the research would be able to provide recommendations based on the results of this investigation.

Although many authors highlighted the role of technology in customer services (Elam \& Morrison, 1993; El Sawy \& Bowles, 1997), many other investigated various issues related to customer service, but only few dealt with empirical research investigating the effect of technology on customer service performance (Lemon \& Verhoef, 2016). The current research aims to fill this gap through investigating the effect of e-management on customer service performance.

The importance of current research stems from lacking studies that focus on e-management in the Arab countries, and particularly in Egypt. Therefore, this research may be considered as a starting point for further research needed to cover in depth the issues affecting the adoption of e-management (which are not discussed in this research). Also, the importance of this research can be derived from its findings, which will be considered as an incentive not only for academics, but, also for business organizations managers and decision makers to investigate deeply in a series of other researches the issues related to the adoption of e-management. Moreover, the current study adds to the literature a new knowledge through dealing with the subject of e-management in relation to customer service performance. In addition to that, the current study provides a theme to prove the effect e-management has on customer service performance.

The main question that the current research aims to investigate and try to answer would be: is there a statistically significant relationship between e-management and customer service performance? 


\section{Literature Review}

Current research aims to investigate the effect of e-management on customer service performance; thus, the following literature review covers the most important issues related to the topic of this research study needed to proceed with such objective. The topics that will be covered in the following literature review section are: e-management, challenges of e-management, and the relationship between e-management and customer service.

\section{E-management}

Alaagez (2011) declared that e-management is a process through which management manages. Also, it is an integrated electronic system that relies on information technology to improve the various administrative processes within the organization. He indicated that the idea of e-management goes far beyond the concept of automation of the work within the organization, to include data and information integration between different departments as well as using such data and information in guiding the policies and procedures of the organization towards achieving its objectives and providing the necessary flexibility to respond to the internal and external variables.

In the same context, Hai (2007) illustrated that e-management implies the use of e-capabilities through the adoption of information and communication technology (ICT) solutions in order to improve management performance, simplify the routine procedures, as well as making the data accessible to users anytime anywhere. Moreover, he indicated that e-management would be considered as the backstage information systems that support the management of the business organization, including tools for communication, coordination, and collaboration.

Ellatif and Ahmed (2013) have explained that it was always noted that the concept of e-management is confused with the concepts of e-business, e-commerce and other similar concepts within the digital world. The authors refer to the International business machine (IBM) organization, which has identified e-business as a comprehensive flexible approach to distribute the value of distinguished works by linking electronic systems to operations through which basic activities of business are performed. IBM has identified e-commerce as a commercial transactions conducted electronically through electronic devices. Also, IBM has determined e-management as a managerial concept, hardware and software systems, and functional configuration and mechanisms as well as activities that depends in its operation on technology to achieve predetermined objectives. The authors illustrated nowadays that the transition to e-management is a major competitive force organizations are forced to think about because of the fast expansion in ICTs and the widespread of the technological revolutions worldwide as well as the enormous increase in the size of information flow. Implementation of e-management mandates innovation culture to prevail inside business organizations. Workforce should think out of the box while taking their deep look into the reality of their business organizations, this thinking approach will allow them to consider all issues surrounding them in the environment, both inside and the outside, thus taking the best actions.

\section{E-management Challenges}

Worldwide challenges are forcing business organizations to adopt major changes such as globalization, recent innovations, competition, as well as changing economic structures. Businesses have to be changed by adopting innovative strategies in order to improve their efficiency and effectiveness (Oppong, Yen, \& Merhout, 2005).

With reference to Shakkah and Algamdi (2016), in addition to the recent and modern ICTs changes, worldwide challenges have affected the environment and function of e-management; thus creating a new working context as follows:

- Change from independent computerized systems into a networked system have created ICT systems those are an electronic fabric connecting core business systems.

- Change from non-electronic management systems to smart e-management systems allow dealing with information sources that produce smart elements such as databases and software that search for information.

- Change from batch processing, conducting gradually in batches, to online real-time processing suits 
the changing and rapid nature of doing business which requires constant updating.

- Change working environment to make use of different networks, such as intranets and extranets, allowing the online link of systems and databases, thus providing information instantly as needed.

- Change to work using client/server environment enhance security as well as the ability to serve many users.

- Change from centralized computing to distributed computing allows flexible and team-work structures instead of individual tasks.

Ibrahim (2011) have illustrated that it is very difficult to draw a conclusion about the status of e-management in the Arab countries due to many reasons including the generalization nature of the topic of e-management, as well as the variety of domains constituting its field such as ICT, e-commerce, e-government, and management.

Moreover, he determined that it is worth mentioning that the Arab countries may have limitations regarding the application of e-management related mainly to a number of issues. One of the most significant limitation is the technology limitation, as some Arab countries has an outdated ICTs infrastructure that limit their capabilities in adopting the required services needed for implementing e-management. Another limitation is the culture limitation, as Arab countries vary significantly in individuals' culture (traditions in the unique Arabia aspects of life), as well as the organizational culture (values and traditions shared by workforce), and vary as well in their administrative methodologies in performing daily activities; individuals affects organizations and organizations affects workforce. In order to keep pace with recent innovations, culture must provide Arabs with innovative thinking tools, and also provide decision makers with knowledgeable capabilities that aid them in developing and using e-management systems.

Moreover, socio-economic limitation is very important, as adopting recent technologies needed to implement e-management systems takes place at levels of both organizations and society; thus transforming them into information community and information economy. Having the right environment leads to the success of e-management implementation; therefore, it is very important to ensure changing the attitudes of the collective society to adopt recent innovations and especially e-management.

In the same context, Maher (2010) has indicated that regardless of the limitations of e-management adoption in Arab environment, the chances of successful e-management are proved to be very high, as there is a serious commitment and established innovations in the administration of the business organizations as well as the governmental entities. It is concluded from the Arab experiments with e-management, that the following are the requirements of its success:

- Having development strategy for recent innovative technologies.

- Investing in the appropriate facets of ICTs infrastructures.

- Having strategies for building and improving culture through innovations.

- Re-engineering traditional work activities to match the recent innovative environments.

\section{E-management and Customer Service}

The literature shows that many worldwide organizations adopted e-management as a result of recognizing its positive effects on employees' performance (Cordella, Martin, Shaikh, \& Smithson, 2011). E-management - as one of the significant outcomes of the digital world - is considered as an e-mechanisms. Moreover, digital world has changed the theoretical and practical applications of e-management through introducing new systems, tools, and models, which are considered as new ways of competition based on innovation (Shakkah \& Algamdi, 2016).

E-management takes care of using ICTs in making the core business functions; thus streamlining business processes in order to maintain e-records, and improving the flow and the integration of information (Kim \& Koh, 2004). These ICTs are considered as the facilitator of the recent and rapid changes in business environment, ICTs facilitate the creation of a more flexible organization that is capable of achieving competitive advantage and supports management in achieving their goals (Alzubi, Aldhmour, 
\& ALattraqchi, 2016). Moreover, e-management is considered as a key success factor in the competition towards e-business applications, which is the umbrella name for major e-business innovations used for information exchange, on-line collaboration, and to ensure the performance required for e- business success (Berman \& Eaglstein, 2007).

Information is viewed nowadays as a significant resource for generating values throughout the whole organizations and the whole societies; thus affecting human life aspects (Dibrell \& Miller, 2002). This is the reason that ICTs are growing up very fast in our daily lives, aiming at solving businesses and personnel problems in new ways, and it allows linking people and data in new effective ways at a lower cost (Sahuquillo \& Pont, 2003). Same idea was shared by Almutairi (2014), Crowley (2008), and Sharma (2009), as they declared that since the introduction of the Internet, the main focus of current business organizations is the adoption of e-management, as it has the ability to enhance the quality of processes; leading to improving efficiency and effectiveness, the reduction of the expenses, and the increase of the profitability. In the same context, Joshi (2012) and Alshehri and Drew (2010), declared that e-management has several advantages. e-management makes communication fast and easy, e-management makes cost of communication so cheap, shared information easily seen providing transparency, transparency leads to accountability, and providing flexibility due to handling management issues without time and place restrictions.

Recent technological innovations have revolutionized the $21^{\text {st }}$ century, where everything and everyone is getting online, the internet is providing low cost communication mechanism that makes it the most strategic application of technology for businesses. Firms are now searching for means to better interact with customers and influence them, they understand that technology affect customer service performance (Navimipour \& Soltani, 2016).

Customers worldwide require businesses to offer greater quality at lower cost, and businesses understand that achieving these objectives has becoming a significant factor to acquire competitive advantage and compete globally (Bergek, Hekkert, \& Jacobsson, 2008). Also, most businesses organizations are recognizing customer service as a significant strategic issue used to measure competitiveness of the customer service process (Ray, Muhanna, \& Barney, 2005; Rust, Zeithaml, \& Lemon, 2000; Szymanski \& Henard, 2001; Zeithaml, 2000).

In order for businesses to become efficient and be able to contribute to the worldwide competitive markets where customers' expectations are continually rising, adoption of recent innovative technologies is critical (Sharabi, 2013). Literature is rich with authors who agree that innovative technologies are an important ingredient for improving customer service performance (Gunawardhana, 2018; Addas \& Pinsonneault, 2016; Melville, Kraemer, \& Gurbaxzni, 2004; Rai, Patnayakuni, \& Seth, 2006). Moreover, they recognized that recent technology adoption significantly enhance customer relationship quality and outcomes (Darajeh \& Tahajod, 2010).

Many authors have illustrated that business firms have used innovative technology to impact customer service (Karimi, Somers, \& Gupta, 2001; Bradely, Hausman, \& Nolan, 1993; Lohse \& Spiller, 1998; Porter, 1986; Sweat \& hibbard, 1999; Krishnan, Ramaswamy, Meyers, \& Damian, 1999; Furey, 1991). Recent ICTs empowers customers more than ever as the Internet allows continuous contact with them anytime anywhere (Jesu, Gao, Melero, \& Sese, 2019; Chen \& Nath, 2016; Takieddine \& Sun, 2015). Moreover, authors have determined that recent innovative technologies improve customer services expertise and performance in many ways as follows:

- Increasing convenience of provided services, better customer service management, and ultimately increasing the offered services (Furey, 1991),

- Changing standards of competition through offering easy information sharing, reducing costs significantly, reducing cycle times significantly, and ultimately improving customer satisfaction, loyalty and retention (Cash, McFarlan, McKenney, \& Applegate, 1992; Choi, 2018; Salomann, Dous, Kolbe, \& Brenner, 2005),

- Enhancing customer service by raising entry barriers, enhancing productivity, and ultimately generating revenues (Fitzsimmons \& Fitzsimmons, 1997; Lai, Huang, Lin, \& Kao, 2011),

- Enhancing customer service quality, reducing customer service cost, aiding in acquiring new customers, tracking consuming behavior, better understanding customer needs, and customizing the required services and activities (Navimipour \& Soltani, 2016), 
- Making customer services cheaper, easier, faster, and more accurate. Moreover, helping to reduce workload and involvement of human and physical resources (Gunawardhana \& Perera, 2015; Choi \& Ryu, 2015; Choi \& Shin, 2012),

- Increasing salespeople's customer orientation (Reychav \& Weisberg, 2009),

- Enhancing customer service capabilities, and ultimately affect customers' behavior (Setia, Venkatesh, \& Joglekar, 2013),

- Increasing service expertise (Choi \& Ryu, 2015), and

- Enhancing the organizational agility (Mao, Liu, \& Zhang, 2015).

\section{Research Methods}

\section{Approach}

This research used the descriptive analytical approach. Data collected using questionnaire instrument, which was designed and tested before its distribution to study sample. Statistical Package for Social Science (SPSS V. 25) was used in coding and analyzing the data in light of the questions of study instrument. The probability level for a test of statistical significance for the study is $p<.05$, to ensure $95 \%$ confidence in generalization of the findings. Descriptive statistics were used for data analysis of the collected data. The statistical methods used for data analysis are:

- Frequencies, relative frequencies, percentages, averages, and the order of the responses for the pilot test data.

- Pearson correlation coefficient used to test the validity of the instrument.

- Cronbach's Alpha coefficient and confirmatory factorial analysis used to test the reliability of the instrument.

- Central tendency (mean) and dispersion (standard deviation) of data used to know the places of concentration of data and their distance from each other.

- Pearson Coefficient used to measure the degree and type of relationship between variables.

- Simple linear regression and T-Test used to measure the effect of an independent variable on a dependent variable.

- Determinant Coefficient used to determine the extent to which the independent variable can explain the differences in the dependent variable.

- One-way ANOVA used to test the means of independent samples.

\section{Research Hypothesis}

There is a statistically significant relationship between e-management and the performance of customer service.

\section{Population and Sample}

Simple random cluster sampling was used for the selection of the participating business organizations located in Alexandria city of Egypt. The target participating business organizations were chosen randomly based on the list of commercial business organizations obtained through surveying the directory of the Egyptian Ministry of Trade and Industry in November 2018.

The population of the research study consists of 1903 business organizations, and the sample of the study is 485 randomly selected organizations representing $25 \%$ of the total population. A contact was made in order to obtain their approval to start distributing the questionnaires and get their responses. Of the 485 selected organizations, only 391 responded and express their willingness to share in the study. Four follow-up contacts were made in order to ensure the readiness of questionnaires for collection. 263 questionnaires were distributed, but only 226 were collected, and all the collected questionnaires were completed and usable, which represent $86 \%$ response rate representing $30 \%$ of the study population. Data collection took place from December 2018 to January 2019. 


\section{Study Instrument}

The study instrument was designed to explore the views of the employees towards e-management and its effect on customer service performance. The researcher prepared the instrument in its initial stage by reviewing the literature related to the research objectives, as well as by reviewing previous studies in order to analysis existing related instruments. The current research instrument consists of three main sections as follows:

- Part 1: aimed at collecting demographic information about professionals participating in the study, such as gender, age, academic qualification, position, experience, and working function.

- Part 2: aimed at soliciting the opinion of participating professionals regarding the applicability and adoption of e-management, and it consists of 9 statements.

- Part 3: aimed at soliciting the opinion of participating professionals regarding the effect of e-management on the performance of customer service, and it consists of 10 statements.

The instrument was piloted in two distinct ways, it was tested in order to ensure that it is accurate, consistent, the questions reflect the intended meaning of the researcher, and to ensure that this meaning will be understood by anyone reading these questions; thus increasing the instrument validity and reliability. Expert comments were used to check the instrument, as a number of 19 academics expert reviewed the instrument to ascertain its relevance and ability to achieve the intended objectives, then the instrument was evaluated and revised with their comments. This was followed by the distribution of a prototype of the instrument to a number of 25 employees in the participating organizations in order to obtain their observations before the final distribution, both pilot tests were with a return rate of $100 \%$.

the reliability of instrument was calculated as 0.93 using Cronbach's Alpha coefficient and confirmatory factorial analysis, and it was 0.86 for part 2 (applicability and adoption of e-management), while it was 0.94 for part 3 (effect of e-management on the performance of customer service).

The validity of the instrument was calculated using Pearson correlation coefficient between each of the used statements and the complete equivalent part in the instrument. Calculations shows that all the values of correlation coefficients are statistically significant at the level (0.01), and this shows the validity of the instrument.

\section{Data Analysis and Results}

\section{Demographic Information Analysis}

Frequencies and percentages of the research sample were calculated according to the different variables as follows: Gender analysis: distribution of sample shows that $42.9 \%$ are females and the remaining higher portion of $57.1 \%$ as males, as shown in figure 1 .

\section{Sample gender analysis}

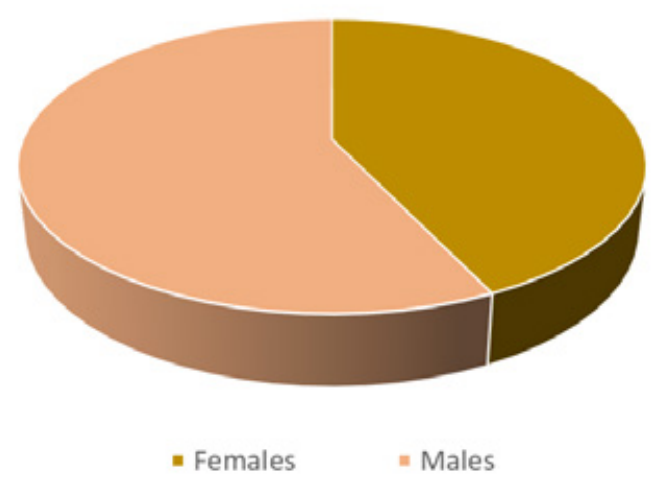

Figure-1. Sample gender analysis 
Age analysis: distribution of sample shows that the percentage of individuals aged over 50 years is $11.1 \%$, individuals aged $40-50$ years as $35.8 \%$, the percentage of individuals aged $30-40$ years $28.3 \%$, while the percentage of individuals under the age of 30 years in the sample is $24.8 \%$. This result indicates the diversity in average ages of the study sample and a relative increase in the average ages, as shown in figure 2 .

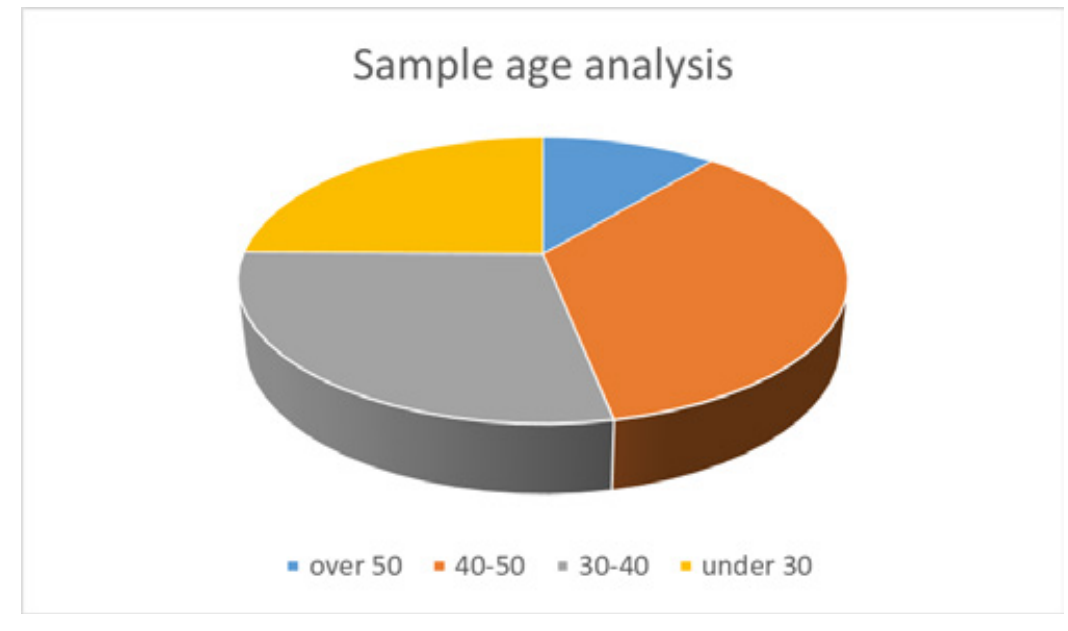

Figure-2. Sample age analysis

Scientific qualification analysis: distribution of sample shows that the percentage of individuals with intermediate and above average qualifications (secondary school) in the sample is $27.4 \%$, basic education (primary \& preparatory school) percentage in the sample is $8 \%$, individuals with a university qualification (Bachelor degree) represented $53.1 \%$, the MSc holders in the sample is $11.1 \%$, while the percentage of the $\mathrm{PhD}$ holders in the sample is $0.4 \%$. It is clear from the previous analysis that the society of current study is well qualified, as shown in figure 3.

Figure-3. Sample scientific qualification analysis

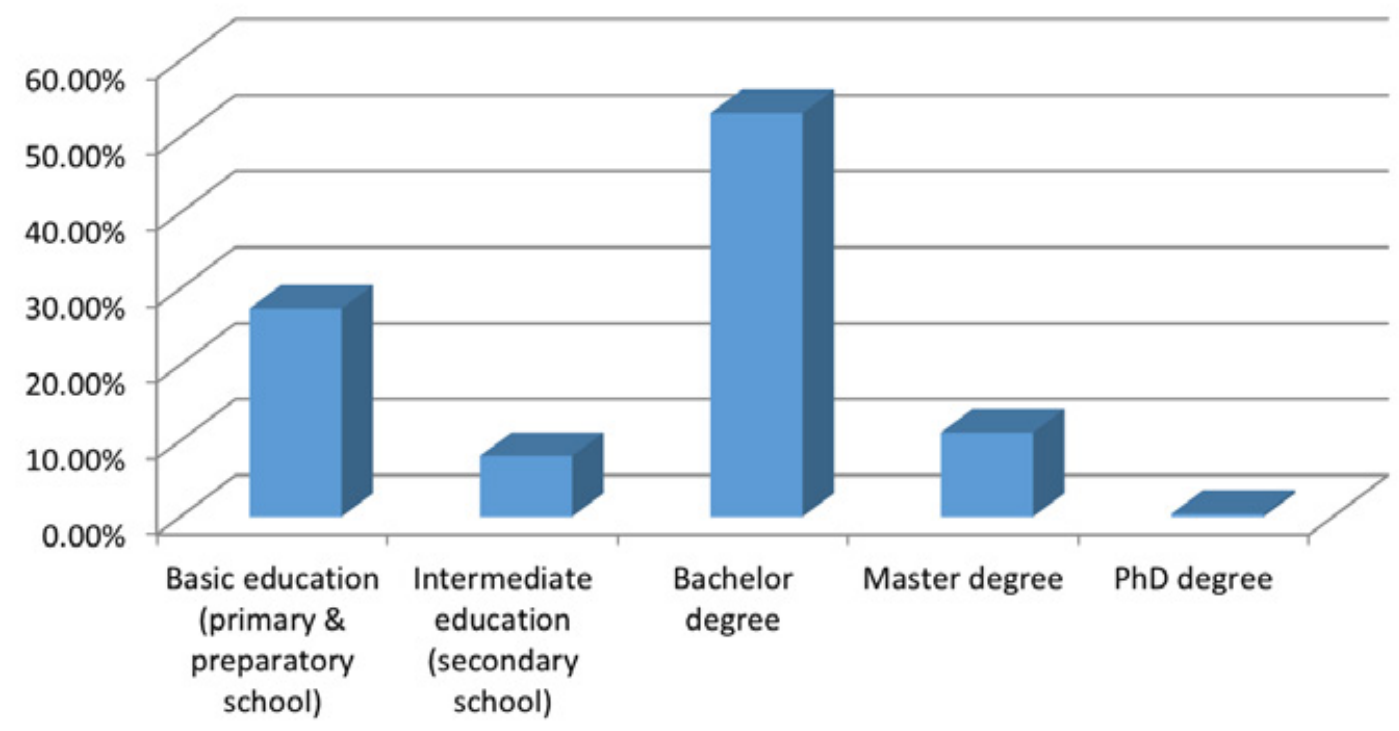

Working experience analysis: distribution of the sample shows that the percentage of individuals with years of experience of 20 years or more is $28.3 \%$, individuals whose years of experience from 15 to less than 20 years is $15.9 \%$, individuals whose years of experience from 10 to less than 15 years is $26.5 \%$, individuals with years of experience from 5 to less than 10 years is $12.8 \%$, and finally individuals with less than 5 years of experience is $16.4 \%$. it is clear that the sample has individuals who have considerable work experience, as shown in figure 4. 


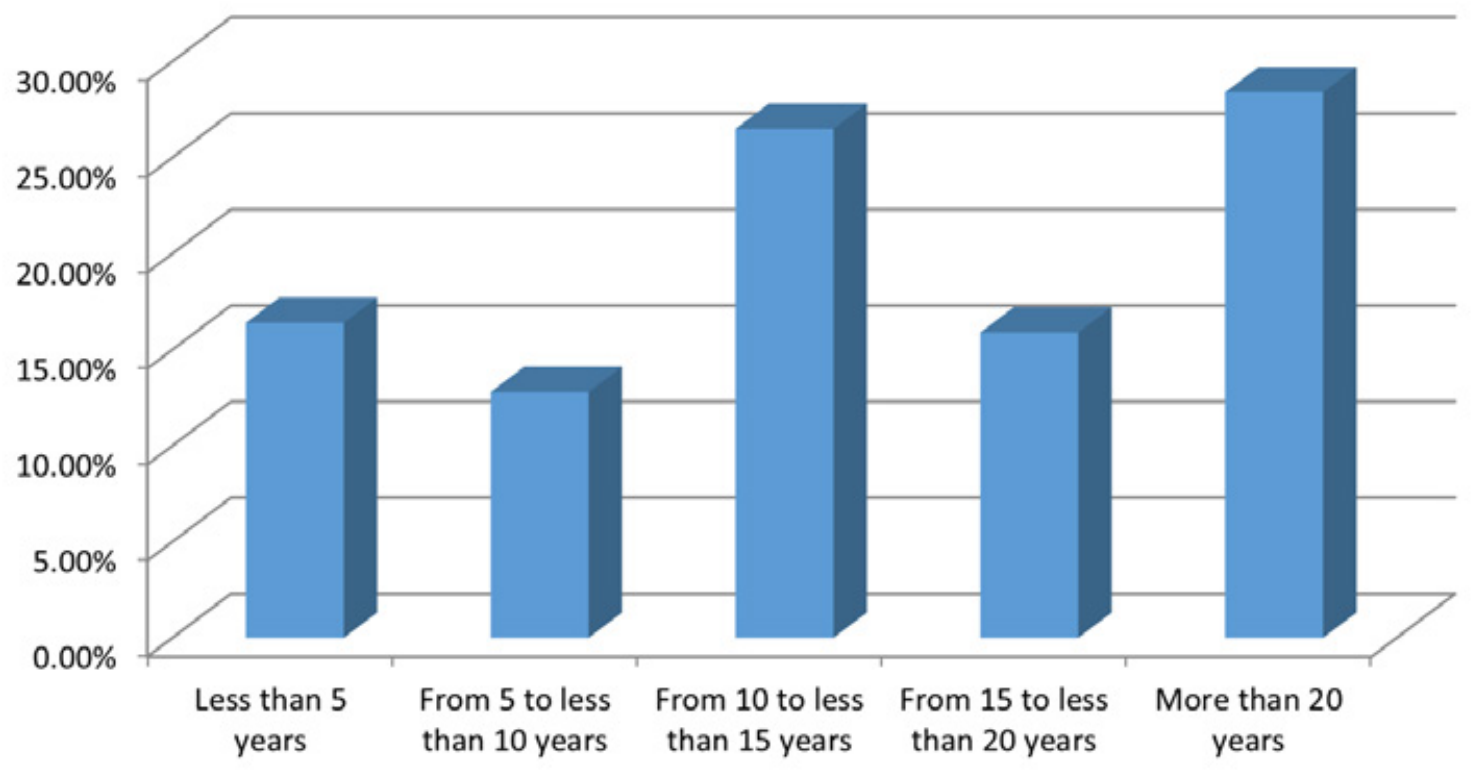

Figure-4. Sample working experience analysis

Working function analysis: distribution of the sample shows that the percentage of individuals who work in "training" function is $5.3 \%$, those who work in "administrative affairs" function is $13.3 \%$, the percentage who work in "informatics" function is $16.8 \%$, the percentage who work in "financial affairs" function is $16.8 \%$, the percentage who work in "planning and statistics" function is $4 \%$, and the percentage who work in "operations and investment" function is $15.5 \%$, as shown in figure 5 .

\section{Sample working function analysis}
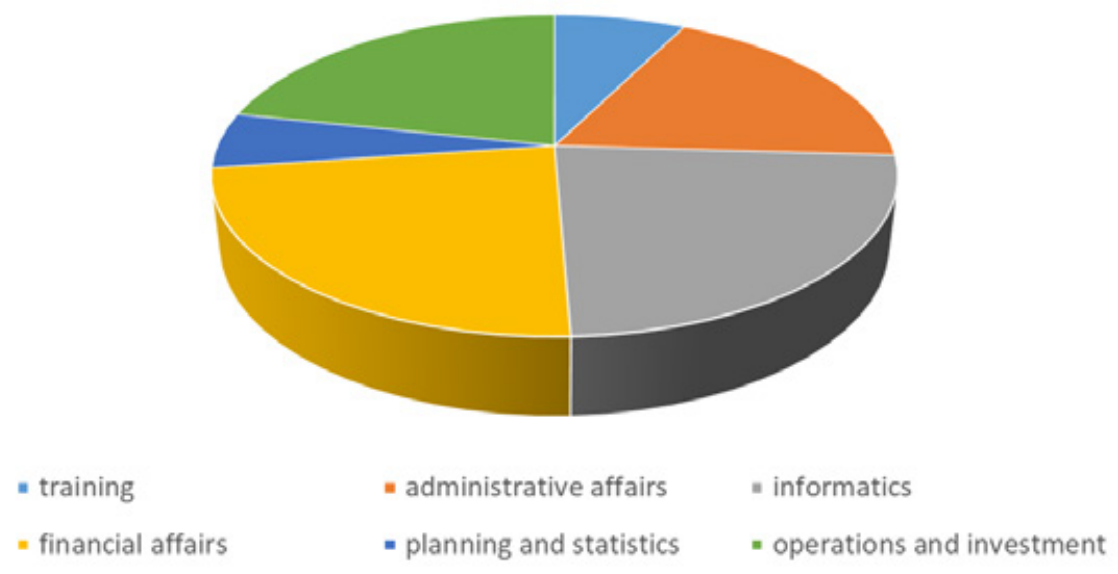

Figure-4. Sample working function analysis

\section{Data Analysis and Discussion}

The results of the descriptive statistics for part 2 of the instrument, which aims at soliciting participant opinions regarding the applicability and adoption of e-management, were examined by comparing the average mean for that part with the mean values of the responses of the participants. From this analysis we can conclude the following results:

Statement 1 "administration aims to replace traditional systems with electronic systems" ranked last according to the average of 3.88 , with a strongly agree rate of $(26.1 \%)$ as well as a strongly disagreeable 
rate of $1.3 \%$. This result indicates that participants believes that the administration is replacing traditional systems with recent electronic systems.

Statement 2 "administration uses electronic communication systems" ranked eighth according to the average of 3.88 , with a strongly agree rate of $19.5 \%$ as well as a strongly disagreeable rate of $0.9 \%$. This result indicates that there is a considerable agreement by participants that the administration uses electronic communication systems.

Statement 3 "administration uses electronic data exchange systems" ranked seventh according to the average of 4.03 , with a strongly agree rate of $19.9 \%$ as well as a strongly disagreeable rate of $0.4 \%$. This result indicates that there is a high degree of participants who believe that the administration uses electronic data exchange systems.

Statement 4 "Administration relies on electronic monitoring systems" ranked fifth according to the average of 4.09 , with a strongly agree rate of $26.5 \%$ as well as a strongly disagreeable rate of $0.9 \%$. This result indicates that there is a great deal of agreement among participants that the administration relies on electronic monitoring systems.

Statement 5 "administration develops Internet strategies" ranked fourth according to the average of 4.15, with a strongly agree rate of 30.1 as well as a strongly disagreeable rate of $0.4 \%$. This result indicates that there is a great deal of agreement among participants that the administration is developing Internet strategies.

Statement 6 "administration develops secure information systems" ranked third according to the average of 4.15 , with a strongly agree rate of $30.5 \%$ as well as a strongly disagreeable rate of $1.8 \%$. This result indicates that there is a great deal of agreement among participants that the administration is developing secured information systems.

Statement 7 "administration is keen to provide modern electronic equipment" ranked first by the average of 4.24 , with a high acceptance rate of $35.8 \%$ as well as a strongly disagreeable rate of $0.9 \%$. This result indicates that there is a great deal of agreement among participants that the need for modern electronic equipment is considered the most important requirements of the success of the applicability of e-management.

Statement 8 "administration is keen to provide the hardware necessary to build information infrastructure" ranked second by the average of 4.19 , with a high acceptance rate of $27.4 \%$ as well as a strongly disagreeable rate of $0.4 \%$. This result indicates that there is a great deal of agreement among participants that the administration is keen to provide the hardware necessary to build information infrastructure required for the applicability of e-management.

Statement 9 "administration is keen to provide modern equipment that facilitate the adoption of modern electronic systems" ranked sixth according to the average of 4.09 , with a strongly agree rate of $28.8 \%$ as well as a strongly disagreeable rate of $0.4 \%$. This result indicates that there is a high degree of approval among participants that the administration is keen to provide modern equipment that facilitate the adoption of modern electronic systems.

The results of the descriptive statistics for part 3 of the instrument, which aims at soliciting participant opinions regarding the effect of e-management on the performance of customer service, were examined by comparing the average mean for that part with the mean values of the responses of the participants. From this analysis we can conclude the following results.

Statement 1 "adopting e-management contributes to the rapid handling and completion of transactions" ranked third by the average of 4.16 , with a high acceptance rate of $30.1 \%$ as well as a strongly disagreeable rate of $1.3 \%$. This result indicates that there is a great deal of agreement among participants that the adoption of e-management leads to faster handling and completion of transactions.

Statement 2 "adopting e-management improves customer service quality" ranked fifth by the average of 4.08 , with a high acceptance rate of $30.5 \%$ as well as a strongly disagreeable rate of $2.2 \%$. This result indicates that there is a great deal of agreement among participants that the adoption of e-management improves customer service quality. 
Statement 3 "adopting e-management contributes to the rapid completion of work as quickly as possible" ranked first by the average of 4.21 , with a high acceptance rate of $33.2 \%$ as well as a strongly disagreeable rate of $1.3 \%$. This result indicates that there is a great deal of agreement among participants that the adoption of e-management leads to the completion of the work as soon as possible.

Statement 4 "adopting e-management increases work accuracy" ranked fourth by the average of 4.14, with a high acceptance rate of $32.7 \%$ as well as a strongly disagreeable rate of $1.8 \%$. This result indicates that there is a great deal of agreement among participants that the adoption of e-management leads to more accurate work.

Statement 5 "adopting e-management contributes to meeting the modern requirements of customers" ranked ninth by the average of 3.99 , with a high acceptance rate of $21.7 \%$ as well as a strongly disagreeable rate of $1.3 \%$. This result indicates that there is a great deal of agreement among participants that adopting e-management leads to the recognition of the modern requirements of customers, and this is constantly increasing.

Statement 6 "adopting e-management contributes to the higher rate of rotation speed" ranked last by the average of 3.81 , with a high acceptance rate of $18.1 \%$ as well as a strongly disagreeable rate of $2.7 \%$. This result indicates that there is a great deal of agreement among participants that adopting e-management leads to higher rate of rotation speed.

Statement 7 "adopting e-management contributes to the fast entry and exit of goods" ranked eighth by the average of 4.02 , with a high acceptance rate of $22.6 \%$ as well as a strongly disagreeable rate of $1.8 \%$. This result indicates that there is a great deal of agreement among participants that adopting e-management achieves fast entry and exit of goods.

Statement 8 "adopting e-management contributes to the fast handling of transportation" ranked seventh by the average of 4.03 , with a high acceptance rate of $22.1 \%$ as well as a strongly disagreeable rate of $0.9 \%$. This result indicates that there is a great deal of agreement among participants that adopting e-management contributes to the fast handling of transportation.

Statement 9 "adopting e-management contributes to the easy connection with customers" ranked second by the average of 4.18 , with a high acceptance rate of $28.8 \%$ as well as a strongly disagreeable rate of $1.3 \%$. This result indicates that there is a great deal of agreement among participants that the adoption of e-management leads to easy connectivity with customers.

Statement 10 "linking with supervision units contributes to the rapid completion of work" ranked sixth by the average of 4.05 , with a high acceptance rate of $24.3 \%$ as well as a strongly disagreeable rate of $1.8 \%$. This result indicates that there is a great deal of agreement among participants that adopting e-management and the link with supervision units contributes to the rapid completion of work.

In order to test the research hypothesis that there is a statistically significant relationship between e-management and the performance of customer service, the researcher used a simple regression model where the dependent variable is the performance of customer service, while the Independent variable is the applicability and adoption of e-management.

Table 1: The correlation and coefficient of determination of research hypothesis

\begin{tabular}{|c|c|c|c|c|}
\hline \multicolumn{4}{|c|}{ Model Summary } \\
\hline Model & R & $\mathbf{R}^{\mathbf{2}}$ & Adjusted $\mathbf{R}^{\mathbf{2}}$ & Std. Error of the Estimate \\
\hline 1 & 0.47 & 0.220 & 0.217 & 5.53198 \\
\hline
\end{tabular}

From table 1 , given the value of $\mathrm{R}^{2}=0.22$, which indicates that the applicability and adoption of e-management is able to explain $22 \%$ of the differences in the performance of customer service. 
Table 2: Analysis of the variance of research hypothesis

\begin{tabular}{|c|c|c|c|c|c|c|}
\hline \multicolumn{7}{|c|}{ ANOVA } \\
\hline \multicolumn{2}{|c|}{ Model } & Sum of Squares & Df & Mean Square & F & .Sig \\
\hline 1 & Regression & 1939.085 & 1 & 1939.085 & 63.363 & 0.000 \\
\hline & Residual & 6855.026 & 224 & 30.603 & & \\
\hline & Total & 8794.111 & 225 & & & \\
\hline
\end{tabular}

In order to test the significance of the model, the null hypothesis will be that the model is not significant, while the alternative hypothesis will be that the model is significant. As illustrated in table 2, given that the value of probabilistic (F-statistic) $=0.00$ is less than $(\alpha=0.05)$ and therefore we can reject the null hypothesis and accept the alternative hypothesis, indicating that the model is significant as the applicability and adoption of e-management has an effect on the performance of customer service.

Table 3: Regression coefficients for research hypothesis

\begin{tabular}{|c|c|c|c|c|c|}
\hline \multicolumn{5}{|c|}{ Coefficients } \\
\hline \multirow{2}{*}{1} & Model & B & Std. Error & T & .Sig \\
\cline { 2 - 6 } & (Constant) & 18.307 & 2.833 & 6.462 & 0.000 \\
\cline { 2 - 6 } & performance of customer services & 0.609 & 0.077 & 7.960 & 0.000 \\
\hline
\end{tabular}

As indicated in table 3 , the value of, given its significance value $=0.000$, which is less than $\alpha=0.05$, and therefore we reject the null hypothesis, meaning that the parameter is significant and the applicability and adoption of e-management contributes to the performance of customer service.

These analytical results assert the research hypothesis that there is a statistically significant relationship between e-management and the performance of customer service, which is also consistent with the literature surveyed in this regard (Almutairi, 2014; Alshehri \& Drew, 2010; Choi \& Ryu, 2015; Choi \& Shin, 2012; Choi, 2018; Darajeh \& Tahajod, 2010; El Sawy \& Bowles, 1997; Ellatif \& Ahmed, 2013; Fitzsimmons \& Fitzsimmons, 1997; Furey, 1991; Gunawardhana, 2018; Jesu et al., 2019; Karimi et al., 2001; Lemon \& Verhoef, 2016; Navimipour \& Soltani, 2016; Ray et al., 2005; Setia et al., 2013; Sharabi, 2013).

\section{Conclusions}

The current research aimed at investigating the effect of e-management on the performance of customer service. The importance of this research stems from the lacking of studies that focus on e-management in Arab countries, and particularly in Egypt. Therefore, this research may be considered as a starting point for further research to cover in depth the issue that affect the adoption of e-management. Also, the findings of this research will be considered as an incentive not only for academics, but also for business organizations' decision makers for the series adoption of e-management. Moreover, this study adds new knowledge through dealing with the subject of the e-management in relation to the performance of customer service, as it provides a theme to prove the effect e-management has on the performance of customer service.

The analysis of the collected data showed that the applicability and adoption of e-management contributes positively to the performance of customer service, as there is a statistically significant relationship between e-management and the performance of customer service. This result is in-line and consistent with the literature surveyed in this regard.

The author suggests for the future extended work following the current study to investigate other issues than customer service in relation to e-management, this will add new knowledge to the literature regarding the effect of e-management to a group of collective related issues, as well as a clear image for the adoption process of e-management in business organizations. 


\section{References}

1. Addas, S., \& Pinsonneault, A. (2016). IT capabilities and NPD performance: examining the mediating role of team knowledge processes. Knowledge Management Research \& Practice, 14(1), $1-20$.

2. Alaagez, E. (2011). Role of organizational culture in the application of e-management. Unpublished Master thesis, Business Administration department, Ghaza University, Ghaza.

3. Almutairi, N. (2014). The impact of organizational culture on the adoption of e-management: evidence from public authority for applied education and training (PAAET) in Kuwait. International Journal of Business and Management, 9(9), 1833-8119

4. Alshehri, M., \& Drew, S. (2010). Implementation of e-government: advantages and challenges, IASK E-ALT conference proceedings, 79-86.

5. Alzubi, K., Aldhmour, F., \& ALattraqchi, H. (2016). An investigation of factors influencing the adoption of electronic management based on the theory of reasoned action (TRA): a case study in the University of technology - Iraq. International Journal of Information, Business and Management, 8(4), 270-286.

6. Bergek, A., Hekkert, M., \& Jacobsson, S. (2008). Functions in innovation systems: A framework for analysing energy system dynamics and identifying goals for system- building activities by entrepreneurs and policy makers. RIDE/IMIT Working Paper No. 84426-008, Institute for Management of Innovation and Technology [Retrieved February 18 $8^{\text {th }}, 2019$ from: http://imit.se/wpcontent/uploads/2016/02/2007_153.pdf].

7. Berman, Y., \& Eaglstein, A. (2007). Policy impact on information technology programming in the social services. Knowledge, Technology and policy, 8(1), 23-32.

8. Bradely, S., Hausman, J., \& Nolan, R. (1993). Globalization, Technology and Competition: The Fusion of Computers and Telecommunications in the 1990s. Boston: Harvard Business School Press.

9. Cash, J., McFarlan, F., McKenney, J., \& Applegate, L. (1992). Corporate Information Systems Management: Text and Cases, $3^{\text {rd }}$ ed., Homewood, IL: Richard D. Irwin.

10. Chen, L., \& Nath, R. (2016). Understanding the underlying factors of Internet addiction across cultures: a comparison study. Electronic Commerce Research and Applications, 17, 38-48.

11. Choi, S., \& Ryu, I. (2015). Leveraging accumulated customer knowledge in electronic knowledge repositories for superior customer service. Pacific Asia Journal of the Association for Information Systems, 25(3), 519-539.

12. Choi, S., \& Shin, S. (2012). Improving service quality using organizational memory in electronic knowledge repositories: focusing on shared service value and knowledge reuse. Korean Journal for Business Administration, 25(9), 3511-3531.

13. Choi, S. (2018). Organizational knowledge and information technology: the key resources for improving customer service in call centers. Information Systems and e-Business Management, 16, 187-203.

14. Cordella, A., Martin, A., Shaikh, M., \& Smithson, S. (2011). Management and innovation of e-business, Undergraduate study in Economics, Management, Finance and the Social Sciences, University of London International Programs.

15. Crowley, M. (2008). E-Governance, prenatal care in Utah. Published by Center for Public Policy \& Administration, University of Utah, 4(6).

16. Darajeh, M., \& Tahajod, M. (2010). Benefits of e-CRM for financial services providers. International Conference on Financial Theory and Engineering (ICFTE), Dubai, United Arab Emirates, 95-99.

17. Dibrell, C., \& Miller, T. (2002). Organization design: The continuing influence of information technology. Management Decision, 40(6), 620-627.

18. El Sawy, O., \& Bowles, G. (1997). Redesigning the customer support process for the electronic economy: insights from storage dimensions. MIS Quarterly, 21(4), 457-483.

19. Elam, J., \& Morrison, J. (1993). United services automobile association (USAA). Harvard Business School Case, 9-188-102, Boston.

20. Ellatif, H., \& Ahmed, S. (2013). E-Management: configuration, functions and role in improving performance of Arab institutions and organization. International Journal of Computer Applications, 80(6), 33-40. 
21. Fitzsimmons, J., \& Fitzsimmons, M. (1997). Service management: operations, strategy, and information technology, $2^{\text {nd }}$ ed. New York: Irwin/McGraw-Hill.

22. Furey, T. (1991). How information power can improve service quality. Planning Review, 19(3), 24-26.

23. Gunawardhana, D., \& Perera, C. (2015). A study of the usage of information systems in higher education: An exploratory review. International Journal of Advanced Studies in Computers, Science and Engineering, 4(4), 15 -20.

24. Gunawardhana, D. (2018). Improving the Service Quality of Higher Education Institutions: Special reference to Information Systems. International Journal of Advanced Studies in Computer Science and Engineering - IJASCSE, 7(11), 13-18.

25. Hai, J. (2007). Fundamental of Development Administration. Selangor, Scholar Press. ISBN 978967-5-04508-0.

26. Ibrahim, K. (2011). Management and leadership and the Nile Valley for human development, Cairo - Egypt.

27. Jesu, C., Gao, L., Melero, I., \& Sese, J. (2019). What drives consumers' active participation in the online channel? Customer equity, experience quality, and relationship proneness. Electronic Commerce Research and Applications, 100855.

28. Joshi, A. (2012). Advantages of e-governance. E-Governance in India, Blog. [Retrieved January 15th, 2019 from: http://indiaegovernance.blogspot.com/2008/03/advantages-of-e-governance.html.

29. Karimi, J., Somers, T., \& Gupta, Y. (2001). Impact of information technology management practices on customer service. Journal of Management Information Systems, 17(4), 125-158.

30. Kim, Y., \& Koh, J. (2004). Knowledge sharing in virtual communities: an e-business perspective. Expert Systems with Applications, 26(2), 155-166.

31. Krishnan, M., Ramaswamy, V., Meyers, M., \& Damian, P. (1999). Customer satisfaction for financial services: the role of products, services, and information technology. Management Science, 45(9), 1194-1209.

32. Lai, M., Huang, H., Lin, L., \& Kao, M. (2011). Potential of organizational memory for creating service performance: a cross-level analysis. Expert Systems with Applications, 38(8), 493-498.

33. Lemon, K., \& Verhoef, P. (2016). Understanding customer experience throughout the customer journey. International journal of marketing studies, 80, 69-96.

34. Lohse, G., \& Spiller, P. (1998). Electronic shopping. Communications of the ACM, 41(7), 81-87.

35. Maher, A., (2010). Principales of management science and skill. University House, Alexandria.

36. Mao, H., Liu, S., \& Zhang, J. (2015). How the effects of IT and knowledge capability on organizational agility are contingent on environmental uncertainty and information intensity? Information Development, 31(4), 358-382.

37. Melville, N., Kraemer, K., \& Gurbaxzni, V. (2004). Review: information technology and organizational performance - an integrative model of IT business value. MIS Quarterly, 28(2), $283-322$.

38. Navimipour, N., \& Soltani, Z. (2016). The impact of cost, technology acceptance and employees' satisfaction on the effectiveness of the electronic customer relationship management systems, Computers in Human Behavior, 55(B), 1052-1066.

39. Oppong, S., Yen, D., \& Merhout, J. (2005). A new strategy for harnessing knowledge management in e-commerce. Technology in Society, 27(7), 413-435.

40. Porter, M. (1986). Competition in Global Industries. Boston: Harvard Business School Press.

41. Rai, A., Patnayakuni, R., \& Seth, N. (2006). Firm performance impacts of digitally enabled supply chain integration capabilities. MIS Quarterly, 30(2), 225-246.

42. Ray, G., Muhanna, W., \& Barney, j. (2005). Information Technology and the Performance of the Customer Service Process: a resource-based analysis. MIS Quarterly, 29(4), 625-652.

43. Reychav, I., \& Weisberg, J. (2009). Going beyond technology: knowledge sharing as a tool for enhancing customer-oriented attitudes. The international journal of Information Management, 29(5), 353-361.

44. Rust, R., Zeithaml, V., \& Lemon, K. (2000). Driving customer equity: how customer life-time value is reshaping corporate strategy, Free Press, New York.

45. Sahuquillo, J., \& Pont, A. (2003). Modeling users' dynamic behavior in web application environments. Polytechnic University of Valencia. 
46. Salomann, H., Dous, M., Kolbe, L., \& Brenner, W. (2005). Rejuvenating customer management: how to make knowledge for, from and about customers' work. European Management Journal, 23(4), 392-403.

47. Setia, P., Venkatesh, V., \& Joglekar, S. (2013). Leveraging digital technologies: how information quality leads to localized capabilities and customer service performance. MIS Quarterly, 37(2), 565-590.

48. Shakkah, M., \& Algamdi, S. (2016). An Investigation for Electronic-Management Use in Educational Projects Management (A Case Study in AL-Baha - KSA). American Journal of Economics and Business Administration, 8(1), 1-8.

49. Sharabi, M. (2013). Managing and improving service quality in higher education. International Journal of Quality and Service Sciences, 5(3), 309-320.

50. Sharma, S. (2009). Theorizing intercultural accommodation in consumer e-commerce. International Journal of E-Adoption, 1(3), 82-91.

51. Sweat, J., \& hibbard, J. (1999). Customer disservice. Information week, June $21^{\text {st }}, 65-78$.

52. Szymanski, D, \& Henard, D. (2001). Customer satisfaction: a meta-analysis of the empirical evidence. Journal of the Academy of Marketing Science, 29(1), 16-35.

53. Takieddine, S., \& Sun, J. (2015). Internet banking diffusion: a country-level analysis. Electronic Commerce Research, 14, 361-371.

54. Zeithaml, V. (2000). Service quality, profitability, and economic worth of customers: what we know and what we need to learn. Journal of the Academy of Marketing Science, 28(1), 67-86. 
Investigating the Effect of E-management on Customer Service Performance

Appendix

Survey cover letter \& Survey Instrument 


\section{Investigating the Effect of E-management on Customer Service Performance}

\section{Survey Cover letter}

\section{Dear Participant:}

My name is Dr. Mohamed Elsaadani; I am a researcher investigating the Effect of E-management on Customer Service Performance. Because you are a member of the selected group of business organizations in Alexandria - Egypt, I am inviting you to participate in this research study by completing the attached survey.

The following questionnaire will require approximately 20 minutes to complete. There is no compensation for responding nor is there any known risk. In order to ensure that all information will remain confidential, please do not include your name. The data collected and its analysis results will be used for research purposes only.

If you choose to participate in this project, please answer all questions as honestly as possible and return the completed questionnaire promptly to your designated department coordinator. Participation is strictly voluntary and you may refuse to participate.

Thank you for taking the time to assist me in my educational endeavors. The data collected will provide useful information regarding the investigating issue of this research.

Sincerely,

Dr. Mohammed A Elsaadani

Assistant Professor - Business Administration Department

Jubail University College - Royal Commission in Jubail

Kingdom of Saudi Arabia

Telephone: +966556945709

Email: saadanim@ucj.edu.sa

December 2018 


\section{Investigating the Effect of E-management on Customer Service Performance}

\section{Survey Instrument}

Part I - Demographic Information

Kindly select the appropriate choice by adding (v) sign

Gender:

Male ( )

Female ( )

Age:

Less than 30 years $\quad(\quad)$

From 30 to 40 years ( )

From 40 to 50 years ( )

More than 50 years $\quad(\quad)$

Highest level of education:

Basic education (primary \& preparatory school)

Intermediate education (secondary school)

Bachelor degree

Master degree

PhD degree

The name of your current position

Number of years of professional experience:

Less than 5 years

From 5 to less than 10 years

From 10 to less than 15 years

From 15 to less than 20 years

More than 20 years 


\section{Part 2 - The Applicability of E-management}

This part of the survey aims at soliciting the opinion of participating professionals regarding the applicability and adoption of e-management, and it consists of 9 statements. Kindly select the appropriate choice that reflects your opinion by adding $(\mathrm{V})$ sign.

\begin{tabular}{|c|l|l|l|l|l|l|}
\hline No & Statement & $\begin{array}{c}\text { Strongly } \\
\text { Disagree }\end{array}$ & Disagree & Neutral & Agree & $\begin{array}{c}\text { Strongly } \\
\text { Agree }\end{array}$ \\
\hline 1 & $\begin{array}{l}\text { the administration aims to replace traditional systems } \\
\text { with electronic systems }\end{array}$ & & & & & \\
\hline 2 & the administration uses electronic communication systems & & & & & \\
\hline 3 & the administration uses electronic data exchange systems & & & & & \\
\hline 4 & administration relies on electronic monitoring systems & & & & & \\
\hline 5 & the administration develops internet strategies & & & & & \\
\hline 6 & the administration develops secure information systems & & & & & \\
\hline 7 & $\begin{array}{l}\text { the administration is keen to provide modern elec- } \\
\text { tronic equipment }\end{array}$ & & & & \\
\hline 8 & $\begin{array}{l}\text { the administration is keen to provide the hardware } \\
\text { necessary to build information infrastructure }\end{array}$ & & & & & \\
\hline 9 & $\begin{array}{l}\text { the administration is keen to provide modern equipment } \\
\text { that facilitate the adoption of modern electronic systems }\end{array}$ & & & & & \\
\hline
\end{tabular}

\section{Part 3 - The Effect of E-management on the Performance of Customer Services}

This part of the survey aims at soliciting the opinion of participating professionals regarding the effect of e-management on the performance of customer service, and it consists of 10 statements. Kindly select the appropriate choice that reflects your opinion by adding $(\sqrt{ })$ sign.

\begin{tabular}{|c|l|l|l|l|l|l|}
\hline No & Statement & $\begin{array}{l}\text { Strongly } \\
\text { Disagree }\end{array}$ & Disagree & Neutral & Agree & $\begin{array}{c}\text { Strongly } \\
\text { Agree }\end{array}$ \\
\hline 1 & $\begin{array}{l}\text { adopting e-management contributes to the rapid } \\
\text { handling and completion of transactions }\end{array}$ & & & & & \\
\hline 2 & $\begin{array}{l}\text { adopting e-management improves customer service quality } \\
\text { adopting e-management contributes to the rapid } \\
\text { completion of work as quickly as possible }\end{array}$ & & & & & \\
\hline 4 & $\begin{array}{l}\text { adopting e-management increases work accuracy } \\
\text { adopting e-management contributes to meeting the } \\
\text { modern requirements of customers }\end{array}$ & & & & & \\
\hline 6 & $\begin{array}{l}\text { adopting e-management contributes to the higher rate } \\
\text { of rotation speed }\end{array}$ & & & & & \\
\hline 7 & $\begin{array}{l}\text { adopting e-management contributes to the fast entry } \\
\text { and exit of goods }\end{array}$ & & & & & \\
\hline 8 & $\begin{array}{l}\text { adopting e-management contributes to the fast } \\
\text { handling of transportation }\end{array}$ & & & & \\
\hline 9 & $\begin{array}{l}\text { adopting e-management contributes to the easy } \\
\text { connection with customers }\end{array}$ & & & & \\
\hline 10 & $\begin{array}{l}\text { the linking with supervision units contributes to the } \\
\text { rapid completion of work }\end{array}$ & & & & \\
\hline
\end{tabular}

Thank you very much for your valuable time 
Investigating the Effect of E-management on Customer Service Performance 